\title{
Invited talk: What can brain imaging add to neuronal and network representations of pain and attention? Karen D Davis*1,2
}

\author{
Address: ${ }^{1}$ Department of Surgery, Institute of Medical Science, University of Toronto, Toronto, Ontario, Canada and ${ }^{2}$ Division of Brain, Imaging \\ and Behaviour Systems, Toronto Western Research Institute, Toronto, Ontario, Canada \\ Email: Karen D Davis* - kdavis@uhnres.utoronto.ca \\ * Corresponding author
}

from Sixteenth Annual Computational Neuroscience Meeting: CNS*2007

Toronto, Canada. $7-12$ July 2007

Published: 6 July 2007

BMC Neuroscience 2007, 8(Suppl 2):S9 doi:10.1 186/147|-2202-8-S2-S9

(c) 2007 Davis; licensee BioMed Central Ltd.

Classic electrophysiological studies laid the groundwork for our understanding of pain mechanisms and the impact of attentional factors. However, with the advent of neuroimaging technologies such as functional MRI, brain mechanism associated with the multidimensional aspects of human pain perception can now be mapped. Our lab is developing models of specific qualities (percept-related fMRI) of the pain experience, how they are impacted by attentional and individual factors in both healthy individuals and chronic pain states. Such models are also informed by single cell electrophysiological recordings in the human brain, and network models of pain and attention we are developing from multivariate analyses. This presentation will provide an overview of these studies. 